\title{
Metal-Free Carbon Quantum Dots Implant Graphitic Carbon Nitride: Enhanced Photocatalytic Dye Wastewater Purification with Simultaneous Hydrogen Production
}

\author{
Lilei Zhang ${ }^{1}$, Jingxiao Zhang ${ }^{1,2}, * \mathbb{D}$, Yuanyu Xia ${ }^{2}$, Menghan Xun ${ }^{2}$, Hong Chen ${ }^{2}$, Xianghui Liu ${ }^{2}$ \\ and Xia Yin ${ }^{3}$ \\ 1 College of Chemistry and Chemical Engineering, Luoyang Normal University, Luoyang 471934, China; \\ zhanglilei@outlook.com \\ 2 College of Food and Drug, Luoyang Normal University, Luoyang 471934, China; \\ xiayuanyu1997@gmail.com (Y.X.); xunmenghan1997@gmail.com (M.X.); chenhong@lynu.edu.cn (H.C.); \\ liuxianghui20200204@gmail.com (X.L.) \\ 3 School of Chemical Engineering and Pharmacy, Wuhan Institute of Technology, Wuhan 430205, China; \\ yinxia33@gmail.com \\ * Correspondence: zhangjingxiao@lynu.edu.cn
}

Received: 13 December 2019; Accepted: 1 February 2020; Published: 5 February 2020

\begin{abstract}
The use of photocatalysts to purify wastewater and simultaneously convert solar energy into clean hydrogen energy is of considerable significance in environmental science. However, it is still a challenge due to their relatively high costs, low efficiencies, and poor stabilities. In this study, a metal-free carbon quantum dots (CQDs) modified graphitic carbon nitride photocatalyst (CCN) was synthesized by a facile method. The characterization and theoretical calculation results reveal that the incorporation of CQDs into the g- $\mathrm{C}_{3} \mathrm{~N}_{4}$ matrix significantly improves the charge transfer and separation efficiency, exhibits a redshift of absorption edge, narrows the bandgap, and prevents the recombination of photoexcited carriers. The hydrogen production and simultaneous degradation of methylene blue $(\mathrm{MB})$ or rhodamine $\mathrm{B}(\mathrm{RhB})$ in simulated wastewaters were further tested. In the simulated wastewater, the CCN catalyst showed enhanced photodegradation efficiency, accompanied with the increased hydrogen evolution rate $\left(1291 \mu \mathrm{mol} \cdot \mathrm{h}^{-1} \cdot \mathrm{g}^{-1}\right)$. The internal electrical field between the $\mathrm{g}-\mathrm{C}_{3} \mathrm{~N}_{4}$ and the CQDs is the main reason for the spatial separation of photoexcited electron-hole pairs. Overall, this work could offer a new protocol for the design of highly efficient photocatalysts for dye wastewater purification with simultaneous hydrogen production.
\end{abstract}

Keywords: photocatalysis; wastewater purification; hydrogen production; carbon quantum dot; graphitic carbon nitride

\section{Introduction}

The application of photocatalysts to purify wastewater with simultaneous hydrogen production has received persistent interest [1]. To efficiently convert solar energy and achieve the dual functions, for example, purifying wastewater and producing hydrogen from wastewater, the photocatalysts must satisfy the following characteristics: First, it must possess suitable bandgap which satisfies not only efficient light absorption but also suitable conduction band (CB) and valance band (VB) potentials for both wastewater purification and hydrogen production and secondly, it should own a high separation and transfer efficiency of photogenerated electrons and holes, because the recombination of photoinduced charges generally takes place at a very fast timescale (ps- $\mu \mathrm{s})$ [2]. On the basis of 
the above characteristics, numerous studies have provided various types of semiconductor-based photocatalysts, such as halide, oxyhalide, metal molybdate, sulfide, metal oxide, and tungstate, in order to achieve higher photocatalytic efficiency [3-5]. Unfortunately, current photocatalysts still have several fundamental problems that need to be solved, such as low photoabsorption efficiency (which leads to the low quantum efficiency), high electron-hole recombination rate, high cost, and poor stability [6]. Thus, it still needs a follow-up study to solve these defects and develop an efficient photocatalyst.

Since the report of Wang and Domen documented that a polymer semiconductor based on defective graphitic carbon nitride $\left(\mathrm{g}-\mathrm{C}_{3} \mathrm{~N}_{4}\right)$ owns the performance of hydrogen evolution from water [7], the research towards this promising nontoxic metal-free photocatalyst has attracted considerable attention, due to its facile synthesis, visible-light responding energy gap $\left(E_{g}=2.68 \mathrm{eV}\right)$, high physicochemical stability, and "earth-abundant" nature [8,9]. More importantly, $\mathrm{g}-\mathrm{C}_{3} \mathrm{~N}_{4}$ is easily fabricated by thermal polymerization of abundant nitrogen-rich precursors such as melamine [9], dicyandiamide [10], cyanamide [11], urea [12], thiourea, and ammonium thiocyanate [13]. Moreover, this material has enormous application potential, such as organic pollutant degradation [14]. However, they still have some fatal defects restricting their practical applications, such as low quantum efficiency, high electron-hole recombination rate, low charge migration rate, high electron-hole recombination rate, the usage of noble metals as cocatalysts or reagents (such as Pt and Pd, which leads to high cost), and small surface area. For example, the quantum efficiency for hydrogen evolution is only $1 \%$, which results in low photocatalytic activity $[15,16]$. Therefore, in order to enhance the application potential of g- $\mathrm{C}_{3} \mathrm{~N}_{4}$, many strategies were developed, such as coupling with other different materials and morphology control [16,17]. Recently, carbon quantum dots (CQDs) have been successfully deposited on the g- $\mathrm{C}_{3} \mathrm{~N}_{4}$ backbone to enhance its photocatalytic activity through increasing the electron transfer and reservoir properties [18-21]. Since then, several types of CQDs modified $g-\mathrm{C}_{3} \mathrm{~N}_{4}$ nanocomposites have been produced and have been proven to possess an impressive performance for photocatalytic dye wastewater purification or solar water splitting. However, to the best of our knowledge, only a few reports have studied both the theoretical basis and the possible applications in dye wastewater purification with simultaneous hydrogen production [22-24].

In this study, one novel CQDs modified $\mathrm{g}-\mathrm{C}_{3} \mathrm{~N}_{4}$ nanosheets $(\mathrm{CCN})$ was fabricated via a facile and environment-friendly approach. The photocatalytic performances were systematically evaluated by decomposing dye wastewater (including rhodamine $\mathrm{B}(\mathrm{RhB})$ and methylene blue $(\mathrm{MB})$ ) and simultaneous hydrogen production. The focus of this research was on the relationship between photocatalytic degradation of dye wastewater and hydrogen production over an as-prepared photocatalyst. The underlying mechanism of the enhanced photocatalytic properties by the $\mathrm{CCN}$ composite system was further deciphered by first-principles calculation, which is essential for understanding the synergistic mechanism of photocatalytic degradation with simultaneous hydrogen evolution.

\section{Results and Discussion}

\subsection{Characterization of Photocatalysts}

The TEM image of the synthesized CQDs (as displayed in Figure 1a) shows that the incomplete combustion of citric acid produces CQDs that are relatively monodisperse, mostly in diameters of 2 to $5 \mathrm{~nm}$. The TG and DTG analytical results (Figure S1 in Supporting Materials) indicated that the synthesized CQDs were stable under nitrogen. From Figure 1b, a two-dimensional (2D) layered structure with chiffon-like ripples and wrinkles could be seen in the $\mathrm{CN}$ sample, which was in agreement with the report [15]. After modification, many particles (dark gray) with diameters of 2 to $5 \mathrm{~nm}$ are non-uniformly decorated on the surface of the $\mathrm{CN}$ (as shown in Figure 1c,e). Comparing Figure $1 \mathrm{~b}$ with Figure 1c-e, we concluded that the particles in Figure 1c should be CQDs instead of g- $\mathrm{C}_{3} \mathrm{~N}_{4}$ quantum dots because the reaction conditions of synthesizing $\mathrm{CN}$ were the same as those of $\mathrm{CCN}$, except that the latter was produced by adding the CQDs as a starting material. The diffraction of 
the $\mathrm{CN}$ (inset images of Figure 1b) exhibited crystalline lobes, while those of the CCN (inset images of Figure 1d) were hazy, indicating that the matrix of the $\mathrm{CCN}$ composite was more disordered to the pure $\mathrm{CN}$ matrix. Additionally, the SEM images of the $\mathrm{CN}$ and $\mathrm{CCN}$ together with element mapping (Figure 1f,g) illustrated that the $\mathrm{N}$ and $\mathrm{C}$ elements appeared in almost the same place, indicating the CQDs were uniformly dispersed on the $\mathrm{g}-\mathrm{C}_{3} \mathrm{~N}_{4}$.

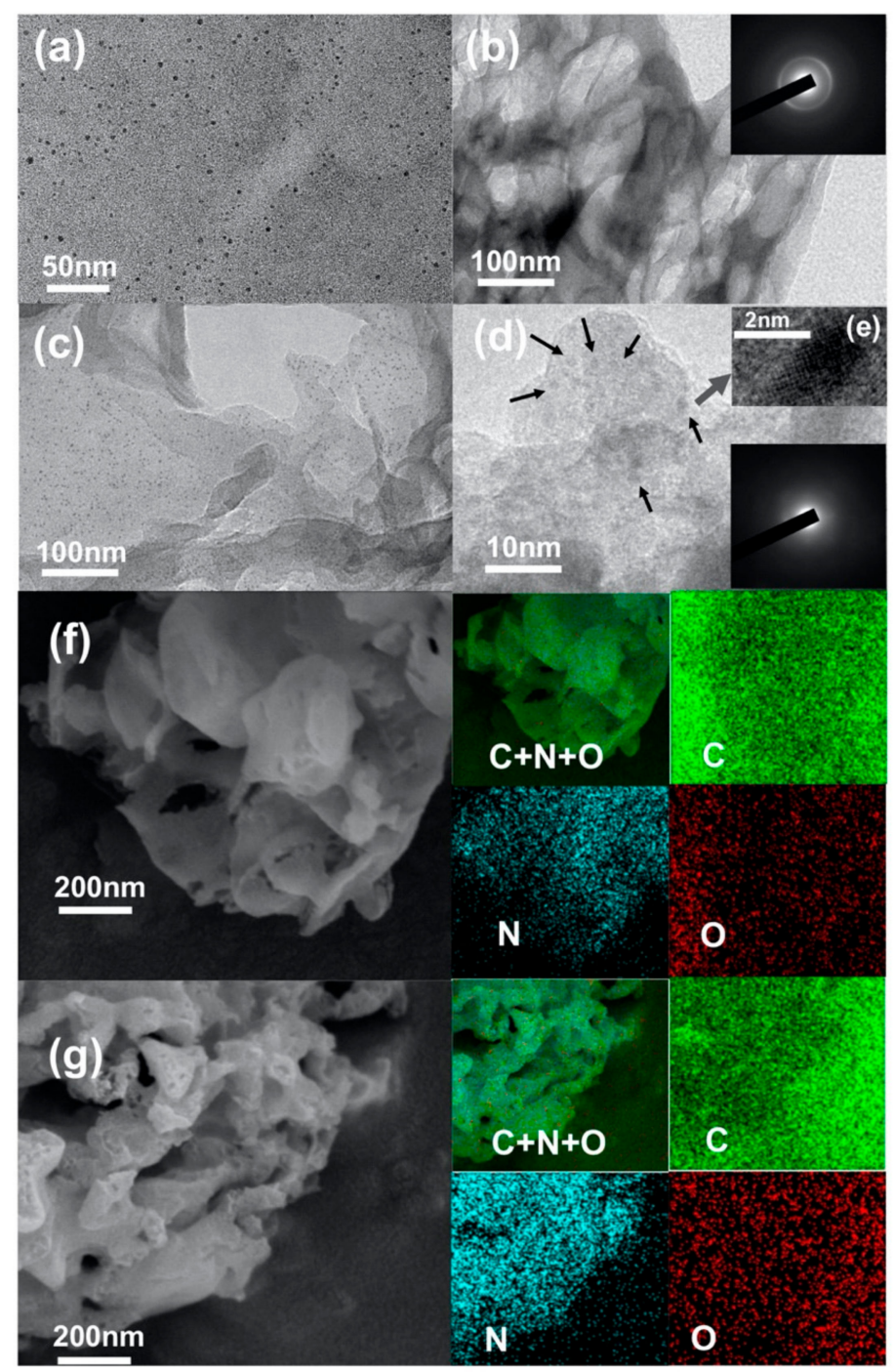

Figure 1. Transmission electron microscope (TEM) images of carbon quantum dots (CQDs) (a); g- $\mathrm{C}_{3} \mathrm{~N}_{4}$ sheets $(\mathrm{CN})(\mathbf{b})$; (c) low- and; (d) high-magnification TEM images of carbon nitride photocatalyst (CCN); (e) HRTEM image of a CQD embedded in CCN, and SEM images together with elemental mapping of $\mathrm{CN}(\mathbf{f})$; and $\mathrm{CCN}(\mathbf{g})$.

Figure 2 shows the XRD patterns of the bulk g- $\mathrm{C}_{3} \mathrm{~N}_{4}$, bulk CQDs-g- $\mathrm{C}_{3} \mathrm{~N}_{4}, \mathrm{CN}$, and CCN. According to the report [25], a stronger diffraction characteristic peak at about $27.5^{\circ}$ and a weaker one at about $13.1^{\circ}$ were observed from the XRD pattern of pure $\mathrm{g}-\mathrm{C}_{3} \mathrm{~N}_{4}$ (as displayed in Figure 2a), which corresponded to $<002>$ and $<100>$ crystal planes of graphitic structure. As shown in Figure 2a, the sharp XRD peaks at $27.5^{\circ}$ corresponded to interlayer stacking of aromatic segments with a distance of $0.329 \mathrm{~nm}$ for g- $\mathrm{C}_{3} \mathrm{~N}_{4}$ and $0.331 \mathrm{~nm}$ for CQDs-g- $\mathrm{C}_{3} \mathrm{~N}_{4}$ from the line width analysis of the $<002>$ diffraction peak using the Debye-Scherrer equation. This phenomenon indicates that due to CQDs modification, the spacing between layers of $\mathrm{g}-\mathrm{C}_{3} \mathrm{~N}_{4}$ becomes bigger. It is worth noting that the $<002>$ peaks of the $\mathrm{CN}$ and $C C N$ decreased and become smaller (Figure $2 b$ ) after the corrosion of nitric acid solution, which illustrates that the $\mathrm{CN}$ and $\mathrm{CCN}$ formed approximate two-dimensional structures. 


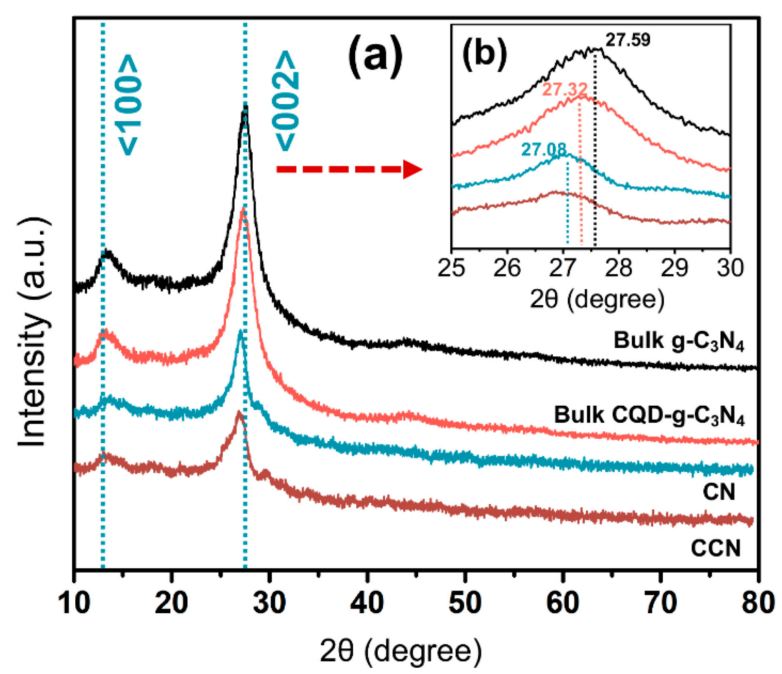

Figure 2. X-ray diffraction (XRD) patterns of the bulk g- $\mathrm{C}_{3} \mathrm{~N}_{4}$, bulk CQDs-g- $\mathrm{C}_{3} \mathrm{~N}_{4}, \mathrm{CN}$, and $\mathrm{CCN}(\mathbf{a})$; and enlarged view of the $25^{\circ}$ to $30^{\circ}$ region (b).

Figure 3a shows the XPS spectra of 4CCN. The XPS survey spectra demonstrate that the CQDs-g- $\mathrm{C}_{3} \mathrm{~N}_{4}$ samples are mainly composed of carbon, nitrogen, and oxygen, and their corresponding photoelectron peaks appear at binding energies of 288 (C 1s), 401 (N 1s), and $530 \mathrm{eV}(\mathrm{O} 1 \mathrm{~s})$. The high-resolution XPS spectra of C 1s (Figure $3 \mathrm{~b}$ ) is deconvoluted into three peaks centered at 284.8, 286.0 , and $288.5 \mathrm{eV}$, respectively. The $\mathrm{C}$ peak at $288.5 \mathrm{eV}$ corresponds to $\mathrm{sp}^{2}$ hybridized carbon $(\mathrm{N}-\mathrm{C}=$ $\mathrm{N})$ of $\mathrm{g}-\mathrm{C}_{3} \mathrm{~N}_{4}$, and the weaker one at $284.8 \mathrm{eV}$ is assigned to graphitic carbon $(\mathrm{C}=\mathrm{C})$ of CQDs. The peak located at $286.0 \mathrm{eV}$ is identified as a small quantity of carbon combined with $\mathrm{C}-\mathrm{N}$ [26]. The $\mathrm{N} 1 \mathrm{~s}$ spectrum (Figure 3c) displays four peaks with binding energies of 398.5, 399.2, 401.2, and $404.8 \mathrm{eV}$, respectively, which are attributed to the $\mathrm{sp}^{2}$-hybridized nitrogen groups $(\mathrm{N}-\mathrm{C}=\mathrm{N})$, tertiary nitrogen atoms $\left(\mathrm{N}-(\mathrm{C})_{3}\right)$, hydrogen-bonded nitrogen groups $(\mathrm{C}-\mathrm{N}-\mathrm{H})$ and the charging effects or positive charge localization in the heterocycles, [27] respectively. Figure 3d represents the $\mathrm{O} 1 \mathrm{~s}$ peaks at 529.5 and $532.6 \mathrm{eV}$, which are assigned to lattice oxygen and adsorbed water, respectively. In the entire spectrum, no characteristic peak related to any other impurities is observed. On the basis of the XPS analysis, it indicates that the as-prepared CCN photocatalyst is free from other unintentional impurities. In addition, the XPS characterization showed that there was no chemical state other than CN and CQDs. Combining with TEM images, we speculated that the CQDs were deposited on the $\mathrm{CN}$ without covalent mixture. After acid treatment, the elemental ratio of bulk g- $\mathrm{C}_{3} \mathrm{~N}_{4}$ was not obviously changed (Table S1 in Supporting Materials), indicating that the increase of $C$ element content is attributed to the CQDs modification. The CQDs content was calculated by the $\mathrm{C}$ and $\mathrm{N}$ element ratio, as shown in Table S1.

\subsection{Photocatalytic Activity}

The photocatalytic activities of different photocatalysts were evaluated by the degradation of organic pollutants (RhB and $\mathrm{MB}$ ) with the simultaneous production of hydrogen. According to the results of the preliminary experiment, the degradation profiles of $\mathrm{RhB}$ and $\mathrm{MB}$ over samples is described by the first-order equation (Equation (1))

$$
\ln \frac{c_{0}}{c}=k t
$$

where $\mathrm{k}$ is the rate constant $\left(\mathrm{min}^{-1}\right), \mathrm{c}_{0}$ is the initial concentration of the $\mathrm{MB}$ or $\mathrm{RhB}$ solution, and $\mathrm{c}$ is the actual concentration of the $\mathrm{MB}$ or RhB solution at a specific time. 

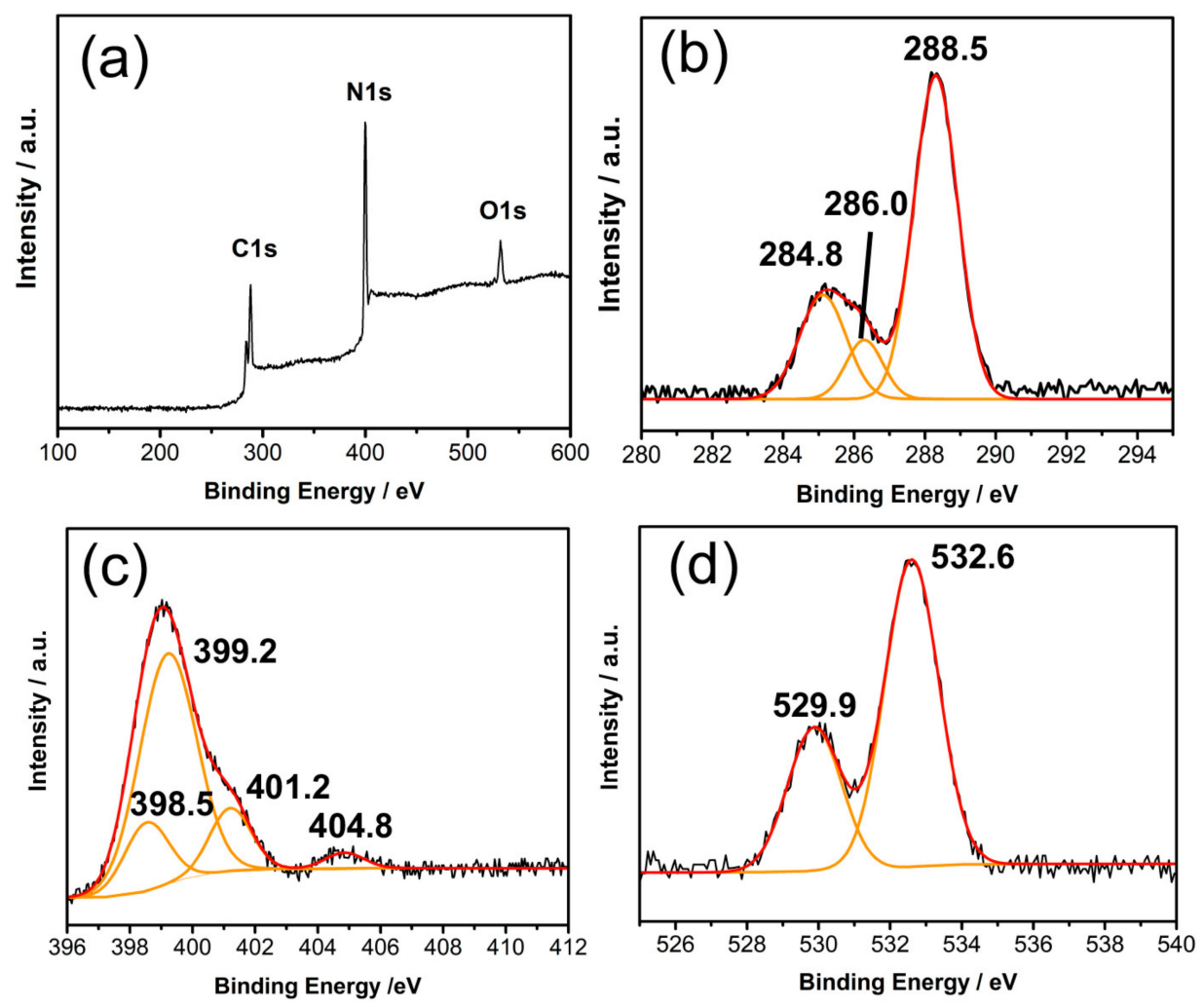

Figure 3. X-ray photoelectron spectroscopy (XPS) survey spectrum of 4CCN (a); the high-resolution XPS spectra of C 1s (b); N 1s (c); and O 1s (d). The black lines are the recorded XPS spectrum, while the red lines are the fitted curves of black lines, deconvoluted into the orange contributions.

The photocatalytic rates of $\mathrm{g}-\mathrm{C}_{3} \mathrm{~N}_{4}$-based samples modified by different concentrations of CQDs were investigated under light irradiation, and the rate constant $\mathrm{k}$ was employed to analyze the catalytic efficiencies quantitatively, as shown in Figure 4a,b. First of all, without any photocatalyst, only MB or RhB did not have any change during light illumination. As shown in Figure $4 \mathrm{a}$, in the presence of $\mathrm{CN}$ under light irradiation, $\mathrm{RhB}$ was found to be degraded with a high degradation rate constant of $\mathrm{k}=0.03 \mathrm{~min}^{-1}$, while a low degradation rate of $\mathrm{MB}$ achieved $\left(0.004 \mathrm{~min}^{-1}\right)$. Subsequently, the photocatalytic degradation rates of $\mathrm{RhB}$ and $\mathrm{MB}$ over $\mathrm{CCN}$ both, first, increase and, then, decrease, with an increase in the amount of CQDs. It is clearly seen that 4CCN $(0.98 \mathrm{wt} \%$ CQDs) catalyst displays the highest degradation rate constants of both $\mathrm{MB}$ and $\mathrm{RhB}$. Therein, this catalyst shows rapid MB degradation with a rate constant of $0.214 \mathrm{~min}^{-1}$, which is almost 54 times higher than $\mathrm{CN}\left(0.004 \mathrm{~min}^{-1}\right)$, while the degradation rate constant of RhB just slightly increases to $0.048 \mathrm{~min}^{-1}$. Thus, the as-obtained CCN photocatalyst enhances the photocatalytic activities for the degradation of MB and RhB.

The photocatalytic hydrogen production activities of $\mathrm{CN}$ in water with different amounts of CQDs were tested by gas chromatography under visible light irradiation, and the results are shown in Figure 4c. It was found that the $4 \mathrm{CCN}$ photocatalyst exhibits the highest hydrogen evolution rate $\left(664 \mu \mathrm{mol} \cdot \mathrm{h}^{-1} \cdot \mathrm{g}^{-1}\right)$. Therefore, in the following experiments, the optimum photocatalyst $4 \mathrm{CCN}$ was employed to decipher the photocatalytic process with simultaneous hydrogen production.

The photocatalytic hydrogen production activities of $\mathrm{CN}$ and $4 \mathrm{CCN}$ in polluted water solutions in different cycles were tested, as displayed in Figure 4d. A comparison of photocatalysts in water solution, shows that both $\mathrm{CN}$ and CCN photocatalysts in RhB and MB solution exhibit the higher hydrogen generation rates. For example, the $\mathrm{H}_{2}$ generation rate of $4 \mathrm{CCN}$ catalyst in RhB solution significantly increased $\left(1291 \mu \mathrm{mol} \mathrm{h}{ }^{-1} \cdot \mathrm{g}^{-1}\right)$, which was higher than that in water $\left(664 \mu \mathrm{mol} \cdot \mathrm{h}^{-1} \cdot \mathrm{g}^{-1}\right)$. Additionally, $\mathrm{CN}$ and $4 \mathrm{CCN}$ showed excellent stability in the process of recycling, according to Figure $4 \mathrm{~d}$. The results of the hydrogen evolution rate demonstrate that modified $\mathrm{g}-\mathrm{C}_{3} \mathrm{~N}_{4}$ by CQDs improves the $\mathrm{H}_{2}$ generation rate in wastewater solutions. In conclusion, after modification by CQDs, 
photocatalytic efficiency of the as-synthesized photocatalyst was more efficient for photocatalytic wastewater purification and energy recovery.
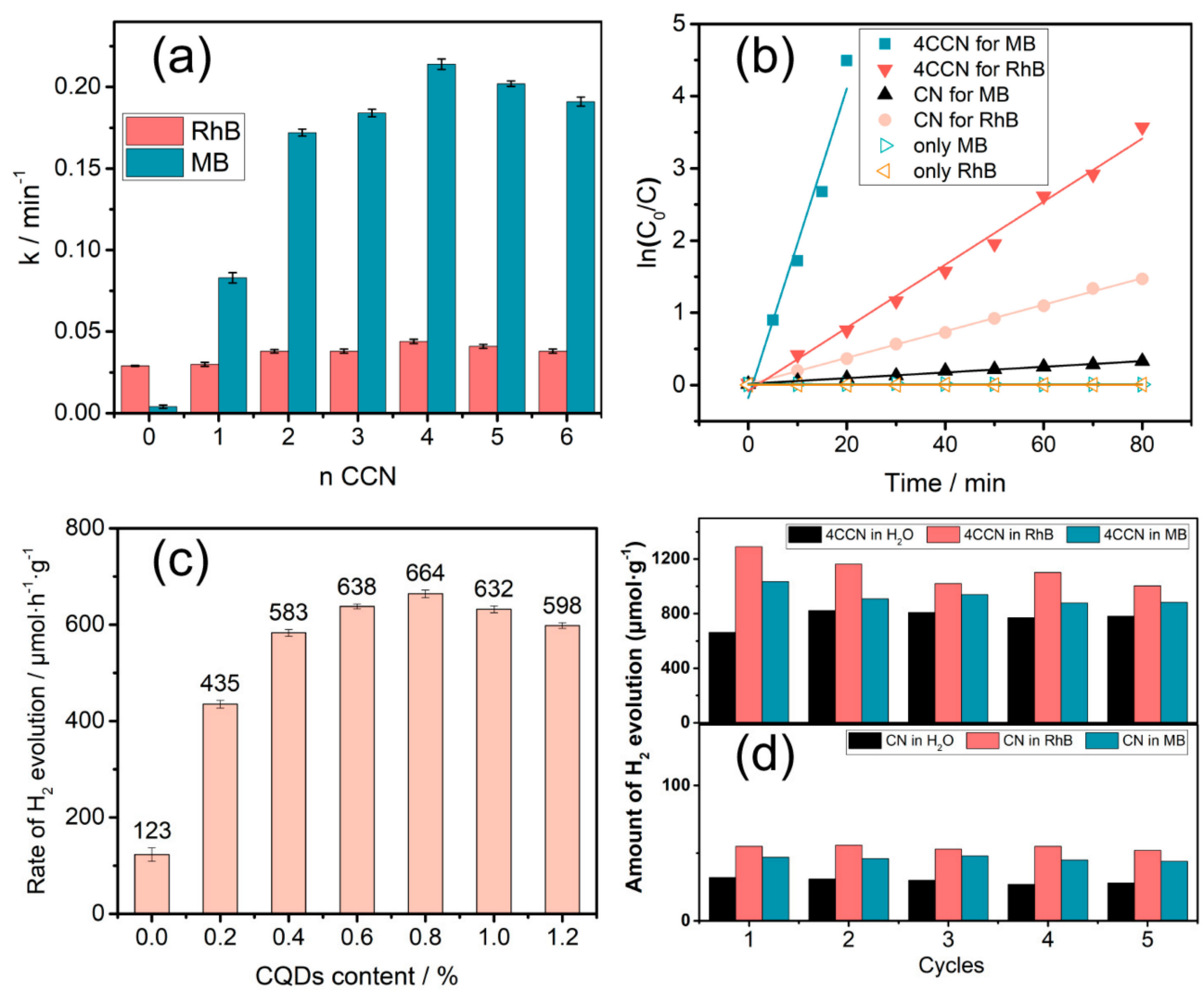

Figure 4. The degradation rate constant of dyes over the $\mathrm{g}-\mathrm{C}_{3} \mathrm{~N}_{4}$-based samples modified by different concentrations of CQDs (a); photocatalytic degradation profiles of RhB and MB over CN and 4CCN (0.98 wt\% CQDs) (b); hydrogen evolution rate of the $\mathrm{g}-\mathrm{C}_{3} \mathrm{~N}_{4}$-based samples modified by different concentrations of CQDs (c); and photocatalytic hydrogen evolution per hour in different cycles over $\mathrm{CN}$ and $4 \mathrm{CCN}$ samples (d). Error bars represent mean \pm s.d. of at least three independent experiments.

A comparative study of the photocatalyst was carried out with different reported photocatalysts (as displayed in Table 1). The results exhibit that $\mathrm{CCN}$ shows superior photocatalytic performance (including $\mathrm{H}_{2}$ evolution rate and dye degradation rates) as compared with the reported photocatalysts.

There are many influencing factors of the photocatalyst performance, such as specific surface area, light absorptivity, separation, and transference of electron-hole pairs, and recombination of photoexcited carriers. The specific surface test results (Table S1 in Supporting Materials) indicate that it is not an essential factor in these $g-C_{3} N_{4}$ based samples due to their close values, so other factors were explicitly investigated.

Ultraviolet-visible spectroscopy (UV-Vis) was used to determine the light absorptivity of all samples, and the results are shown in Figure 5. As displayed in Figure 5a, the incorporation of CQDs into the $\mathrm{g}-\mathrm{C}_{3} \mathrm{~N}_{4}$ matrix leads to an obvious increase in the UV-Vis absorption over the entire wavelength range investigated. The phenomenon indicates that the coupling of CQDs and $\mathrm{g}-\mathrm{C}_{3} \mathrm{~N}_{4}$ is beneficial to improve the light absorption of $\mathrm{CN}$, which implies the enhanced photocatalytic activity. 
Table 1. Comparative photocatalytic results of the present work with reported catalysts for $\mathrm{H}_{2}$ evolution rate and dye degradation rates.

\begin{tabular}{|c|c|c|c|c|c|}
\hline Photocatalyst & Light Source & Catalyst Dose $(\mathrm{g} / \mathrm{L})$ & $\mathrm{H}_{2}$ Evolution Rate & Dye Degradation & Reference \\
\hline $\mathrm{CQDs} / \mathrm{C}_{3} \mathrm{~N}_{4}$ & $\begin{array}{c}\text { AM } 1.5 \text { solar power } \\
\text { system with a cutoff filter } \\
(\lambda>420 \mathrm{~nm})\end{array}$ & 0.4 & $\begin{array}{c}152 \mu \mathrm{mol} \cdot \mathrm{g}^{-1} \cdot \mathrm{h}^{-1} \text { in } 10 \mathrm{mg} \cdot \mathrm{L}^{-1} \text { bisphenol A } \\
\text { solution }\end{array}$ & & [18] \\
\hline $\mathrm{BBT} / \mathrm{TiO}_{2}$ & $\begin{array}{l}300 \text { W Xe lamp with a } \\
420 \text { nm cut-off filter }\end{array}$ & 1 & $\begin{array}{l}\sim 5933 \mu \mathrm{mol} \cdot \mathrm{g}^{-1} \cdot \mathrm{h}^{-1} \text { with Pt as cocatalyst } \\
\text { and TEOA as sacrificial reagent }\end{array}$ & & [22] \\
\hline $5 \mathrm{MoS}_{2} \mathrm{QDs} @ \mathrm{ZnIn}_{2} \mathrm{~S}_{4} @ \mathrm{RGO} 1$ & $\begin{array}{l}300 \mathrm{~W} \text { xenon arc lamp } \\
(320-780 \mathrm{~nm})\end{array}$ & 1.25 & $\begin{array}{l}47.22 \mu \mathrm{mol} \cdot \mathrm{g}^{-1} \cdot \mathrm{h}^{-1} \text { in RhB degradation; } \\
0 \mu \mathrm{mol} / \mathrm{h} / \mathrm{g} \text { in MB degradation }\end{array}$ & $\begin{array}{c}\text { Degradation of MB: } 98.5 \% \\
\text { after } 12 \mathrm{~h} ; \\
\text { Degradation of RhB: } \\
98.8 \% \text { after } 12 \mathrm{~h}\end{array}$ & [23] \\
\hline $\mathrm{CDs} / \mathrm{CdS} / \mathrm{GCN}$ & $\begin{array}{l}300 \mathrm{~W} \text { Xe lamp with a } \\
\text { cutoff filter }(\lambda>420 \mathrm{~nm})\end{array}$ & 0.63 & $3.4 \mu \mathrm{mol} \cdot \mathrm{g}^{-1} \cdot \mathrm{h}^{-1}$ in pure water & & [24] \\
\hline C-dots/g- $\mathrm{C}_{3} \mathrm{~N}_{4} / \mathrm{TiO}_{2}$ & $350 \mathrm{~W}$ Xe arc lamp & 0.63 & $\begin{array}{c}205 \mu \mathrm{mol} \cdot \mathrm{g}^{-1} \cdot \mathrm{h}^{-1} \text { in triethanolamine } \\
\text { aqueous solutions }\end{array}$ & & {$[28]$} \\
\hline $\mathrm{CQDs} / \mathrm{Bi}_{2} \mathrm{MoO}_{6}$ & $\begin{array}{l}300 \mathrm{~W} \text { Xe lamp with a } \\
\text { cutoff filter }(\lambda>420 \mathrm{~nm})\end{array}$ & 1 & & $\begin{array}{l}\text { Degradation of MB: } 100 \% \\
\text { after } 120 \mathrm{~min} ; \\
\text { Degradation of RhB: } 100 \% \\
\text { after } 120 \mathrm{~min}\end{array}$ & [29] \\
\hline CQDs/Ag/Ag $2 \mathrm{O}$ & $\begin{array}{c}150 \mathrm{~W} \text { infrared lamp }(\lambda> \\
700 \mathrm{~nm})\end{array}$ & 0.5 & & $\begin{array}{l}\text { Degradation of MB: } 37 \% \\
\text { after } 150 \mathrm{~min} ; \\
\text { Degradation of RhB: } 48 \% \\
\text { after } 150 \mathrm{~min}\end{array}$ & {$[30]$} \\
\hline $\mathrm{CCN}$ & $\begin{array}{l}300 \mathrm{~W} \text { Xenon lamp } \\
\quad(320-780 \mathrm{~nm})\end{array}$ & 0.33 & $1291 \mu \mathrm{mol} \cdot \mathrm{g}^{-1} \cdot \mathrm{h}^{-1}$ in RhB degradation & $\begin{array}{l}\text { Degradation of MB: } 100 \% \\
\text { after } 20 \mathrm{~min} ; \\
\text { Degradation of RhB: } 100 \% \\
\text { after } 110 \mathrm{~min}\end{array}$ & Present Work \\
\hline
\end{tabular}



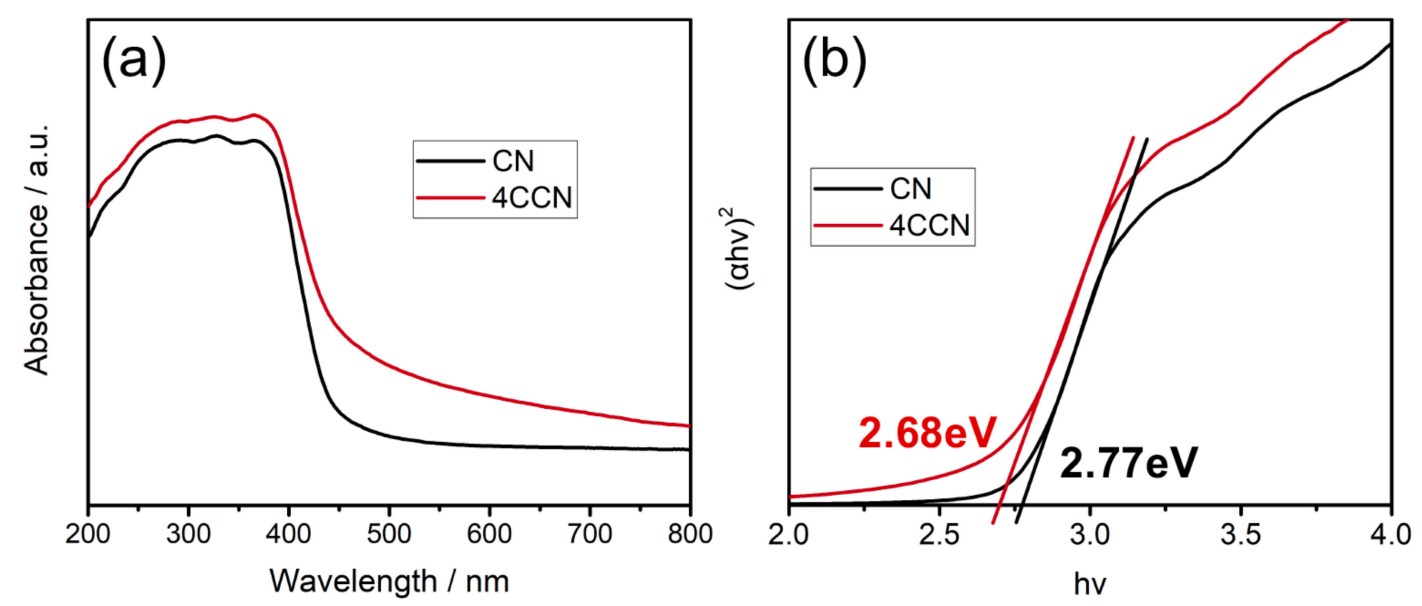

Figure 5. UV-Vis absorption spectra (a) and Tauc plot (b) of CN and CCN photocatalysts.

The bandgap energy (Eg) of $\mathrm{CN}$ and $4 \mathrm{CCN}$ (Figure $2 \mathrm{~b}$ ) is estimated from the Tauc plot method based on Equation (2):

$$
E_{g}=\frac{(\alpha h v)^{r}}{h v}
$$

where $\alpha, h$, and $v$ are the absorption coefficient, Planck constant, and light frequency, respectively. The exponent $r$ is 2 for a direct band gap material and $1 / 2$ for an indirect bandgap material.

As shown in Figure 5b, an excellent linear fit was obtained for both 4CCN and $\mathrm{CN}$ when $\mathrm{r}=2$, which corresponding with the reports in the literature in which $4 \mathrm{CCN}$ and $\mathrm{CN}$ are direct bandgap materials $[20,31]$. By measuring the $x$-axis intercept of an extrapolated line from the linear region of the curve, the Eg value of $4 \mathrm{CCN}$ is, thus, determined to be $2.68 \mathrm{eV}$, which is $0.09 \mathrm{eV}$ smaller than that of pure g- $\mathrm{C}_{3} \mathrm{~N}_{4}$. This result reveals the fact that the $\mathrm{CCN}$ absorbs and utilizes visible light with a larger wavelength, which helps improve the photocatalytic efficiency.

The photoluminescence (PL) emission spectra were performed to study the transfer behavior of charge carriers, with an excitation wavelength of $350 \mathrm{~nm}$. The $\mathrm{CN}$ has a prominent peak at $453 \mathrm{~nm}$ in the PL spectrum, which corresponds to the bandgap recombination of electron-hole pairs. The CCNs have longer excitation wavelength than that of the $\mathrm{CN}$, due to its narrower band gap. Additionally, the intensities of PL spectra for CCN decrease with CQDs content increasing, which indicated that the recombination of charge carriers was prevented effectively in the composite samples. However, when the content of CQDs increases to a certain extent, such as $4 \mathrm{CCN}, 5 \mathrm{CCN}$, and $6 \mathrm{CCN}$, the inhibition of photoelectron recombination no longer increased obviously.

The nanosecond level TRPL was recorded to investigate the transfer dynamics of the carriers in the $\mathrm{CN}$ and $4 \mathrm{CCN}$ under irradiation. As shown in Figure 6b, It can be seen that the lifetimes of the photoexcited charge carriers on $4 \mathrm{CCN}$ are prolonged compared with $\mathrm{CN}$, confirming more excellent photogenerated carriers separation. It indicated that the formation of CQD-g- $\mathrm{C}_{3} \mathrm{~N}_{4}$ heterostructures remarkably promoted charge transfer efficiency, thereby, favoring the photoexcited electron-hole pairs spatial separation and the photocatalytic reactions for dye degradation and $\mathrm{H}_{2}$ evolution.

Figure 7 shows the transient photocurrent response curves of $\mathrm{CN}$ and $4 \mathrm{CCN}$ under intermittently visible light irradiation $(\lambda>420 \mathrm{~nm})$. The $4 \mathrm{CCN}$ sample shows higher photocurrent density, indicating the efficient photogenerated charge transfer between CQDs and g- $\mathrm{C}_{3} \mathrm{~N}_{4}$. Additionally, the photocurrent spike, upon visible light irradiation, can be attributed to the recombination processes on the surface of samples. The photocurrent increases rapidly when the light turns on and, then, the holes accumulate at the photocatalysts' surface competitively recombine with electrons from the conduction of $\mathrm{CN}$, leading to decay of the photocurrent in a short time. After the equilibration of competitive separation and recombination of carriers, the photocurrent reached a constant value. The photoluminescence and photoelectrochemical results confirmed the superior charge transfer and recombination inhibition in the 4CCN composite photocatalyst. 

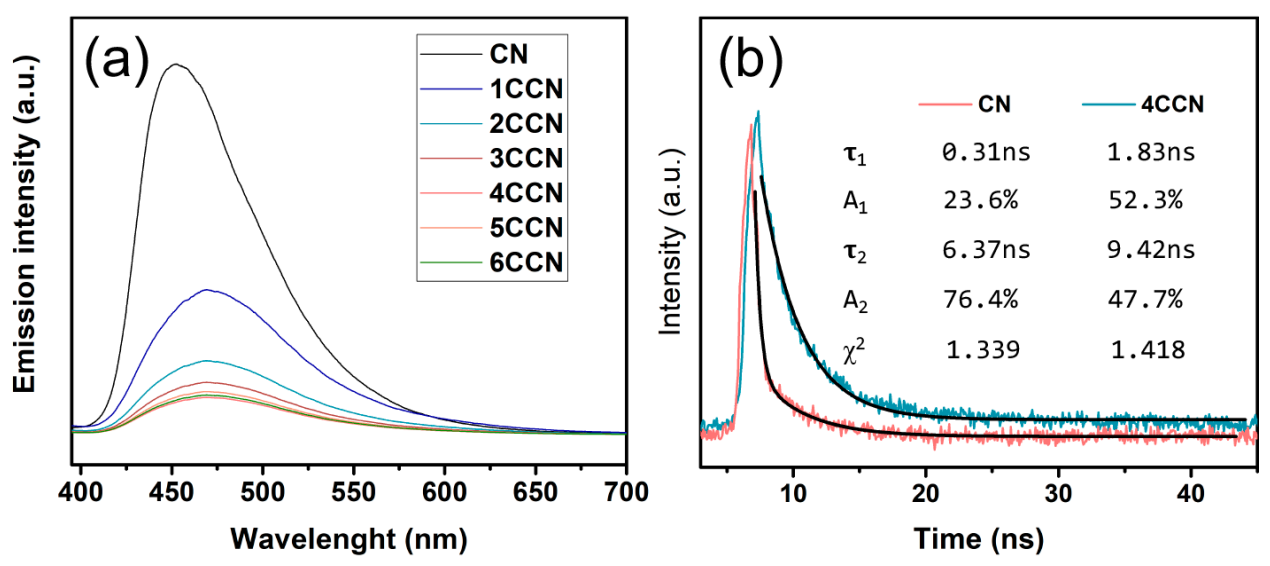

Figure 6. Photoluminescence spectra (a) of $\mathrm{CN}$ and $\mathrm{CCN}$ samples, and time-resolved photoluminescence spectra (TRPL) (b) of the CN and 4CCN samples.

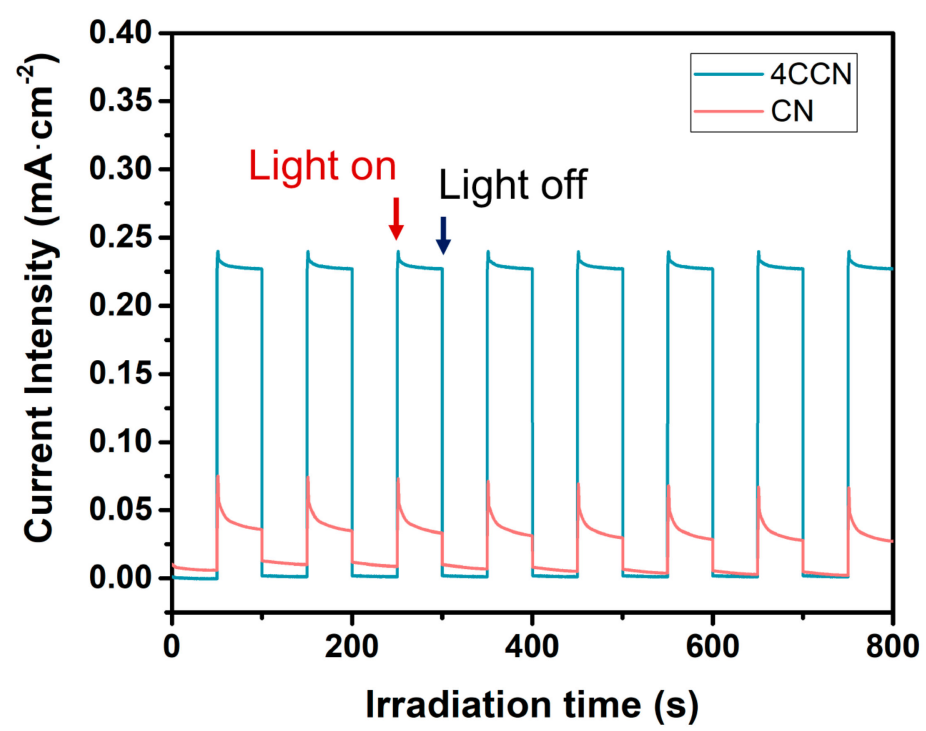

Figure 7. Transient photocurrent responses curves for $\mathrm{CN}$ and $4 \mathrm{CCN}$ samples under visible light irradiation.

\subsection{Theoretical Calculation}

DFT theoretical calculation was performed to illustrate the fundamental reason for the enhanced photocatalytic activity. According to the TEM and XPS characterization, there was no covalent structure between CQDs and g- $\mathrm{C}_{3} \mathrm{~N}_{4}$. In order to examine the local electronic structure information of the stacked structure of CQDs and $\mathrm{g}-\mathrm{C}_{3} \mathrm{~N}_{4}$, a single 2D sheet (Figure $8 \mathrm{~b}$ ) was modeled to represent the $\mathrm{CCN}$ structure. Figure $8 \mathrm{a}, \mathrm{b}$ shows the optimized structures of $\mathrm{CN}$ and $\mathrm{CCN}$. It can be seen that the structure of $\mathrm{g}-\mathrm{C}_{3} \mathrm{~N}_{4}$ has been wrinkled due to the interaction between CQDs and g- $\mathrm{C}_{3} \mathrm{~N}_{4}$. Importantly, on the CQDs surface, the charge was distributed to different regions, the charge accumulated in the region which was facing the cavities in $\mathrm{g}-\mathrm{C}_{3} \mathrm{~N}_{4}$, and the charge depleted in the region which was facing the heptazine unit. When $\mathrm{g}-\mathrm{C}_{3} \mathrm{~N}_{4}$ was excited by photoirradiation, the photoexcited carriers tended to accumulate on CQDs that were facing the cavities of $g-C_{3} \mathrm{~N}_{4}$ under the action of the internal electric field, which lead to the spatial separation of photoexcited electrons and holes. This was the main reason for the recombination prohibition of the photogenerated carriers on the CCN photocatalyst. 

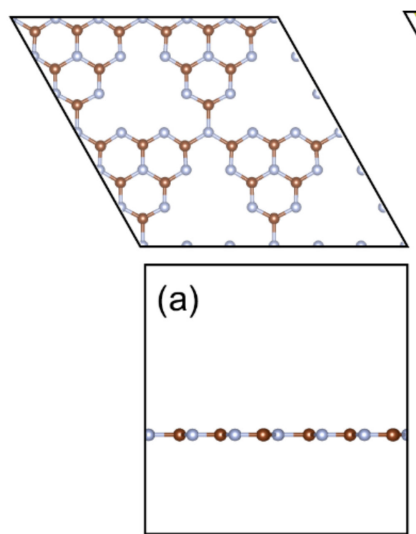

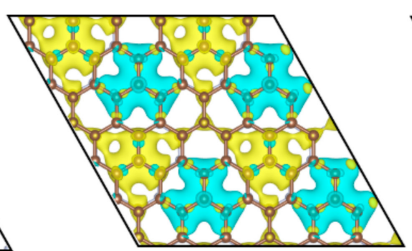

(b)

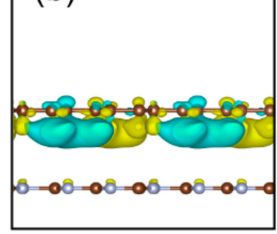

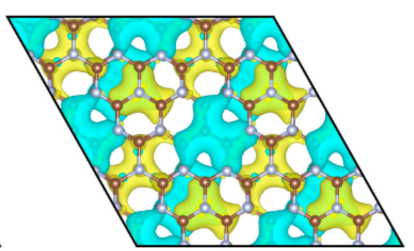

(c)

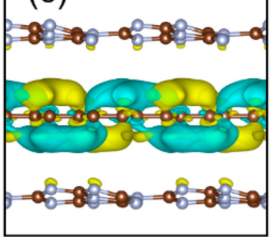

Figure 8. The optimization structures and different charge density of $\mathrm{CN}(\mathbf{a})$ and $\mathrm{CCN}(\mathbf{b}$ and $\mathbf{c})$, yellow (gain electron), cyan (lose electron).

Additionally, it was possible to form the structure of CQDs embedded between $g-\mathrm{C}_{3} \mathrm{~N}_{4}$ layers, and it would change the local electronic structure of CCN. Therefore, the model CQDs sheet between two g- $\mathrm{C}_{3} \mathrm{~N}_{4}$ sheets was constructed, and Figure $8 \mathrm{c}$ shows the optimal structure and different charge density. It can be seen that the charge also depletes or accumulates in different regions on CQDs due to facing cavities or heptazine unit when CQDs insert into two monolayer $g-\mathrm{C}_{3} \mathrm{~N}_{4}$.

According to the frontier molecular orbital theory, the region near the Fermi level is critical for photocatalysis, therefore, some regions were broken out to study the hybridization between CQDs and $\mathrm{g}-\mathrm{C}_{3} \mathrm{~N}_{4}$, as shown in Figure 9. In the region of the dotted circle of $C C N$ (Figure $9 \mathrm{~b}, \mathrm{c}$ ), the peaks of $\mathrm{C}$ in CQDs and g- $\mathrm{C}_{3} \mathrm{~N}_{4}$ almost appear at the same energy level, indicating that there is strong hybridization between CQDs and g- $\mathrm{C}_{3} \mathrm{~N}_{4}$. The interaction between CQDs and g- $\mathrm{C}_{3} \mathrm{~N}_{4}$ could be the reason for the internal electric field between CQDs and $\mathrm{g}-\mathrm{C}_{3} \mathrm{~N}_{4}$, which benefit for the spatial separation of photoexcited carriers.
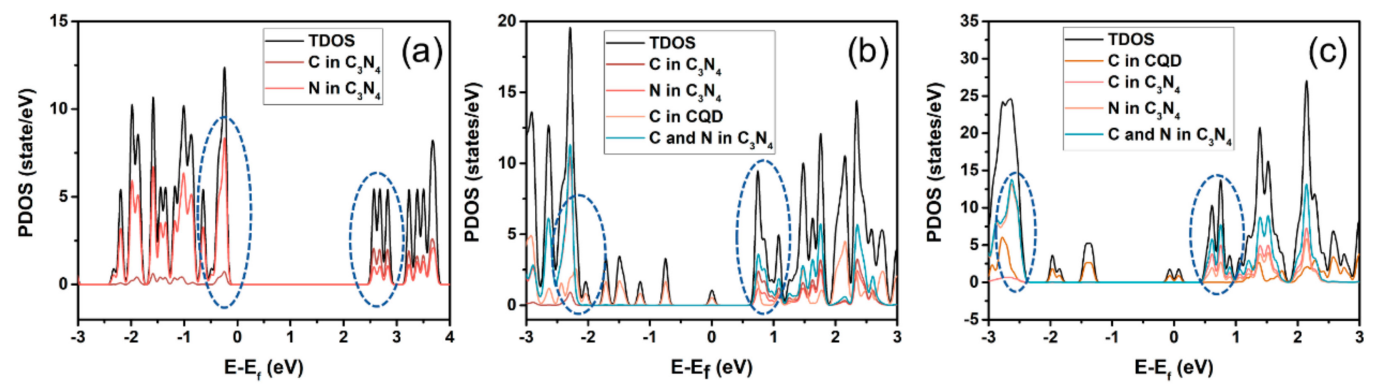

Figure 9. The projected density-of-states for $\mathrm{CN}(\mathbf{a})$ and $\mathrm{CCN}(\mathbf{b}$ and $\mathbf{c})$.

\subsection{The Mechanism of the Enhanced Photocatalytic Activity}

The primary reactive species for the photocatalytic oxidation contains superoxide radicals $\left(\cdot \mathrm{O}_{2}{ }^{-}\right)$, photogenerated holes $\left(\mathrm{h}^{+}\right)$, and hydroxyl radicals $(\cdot \mathrm{OH})$. In order to further understand the reaction mechanisms, three scavengers were used to explore the reactive species in photocatalytic degradation. The $5 \times 10^{-3} \mathrm{~mol} / \mathrm{L}$ solutions of tertiary butanol (TBA), p-benzoquinone (BQ), and ethylenediaminetetraacetic acid disodium (EDTA) were employed as scavengers for $\cdot \mathrm{OH}, \mathrm{O}_{2}{ }^{-}$and $\mathrm{h}^{+}$, respectively. As shown in Figure 10, the photocatalytic degradation rate of RhB and MB degradation over 4CCN was almost invariable with the addition of BQ and TBA. However, the photocatalytic activity decreased with the addition of EDTA, indicating that the photocatalytic process was mainly governed by $\mathrm{h}^{+}$. It is well-established that efficient separation of photoexcited electrons and holes is of great importance for improving the photocatalytic activity. 

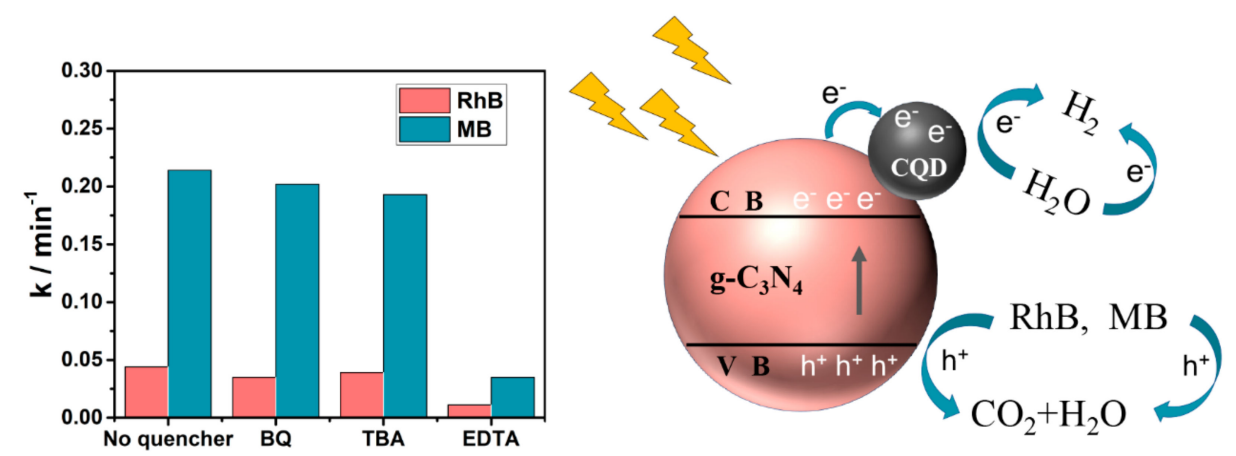

Figure 10. Proposed mechanism for methylene blue (MB) and RhB degradation by CCN under light irradiation.

On the basis of the characterizations mentioned above and the DFT theoretical calculation results, the possible mechanism of charge transfer in $\mathrm{CCN}$ was proposed to dissect the enhanced photocatalytic activity, as shown in Figure 10. Under the influence of the internal electric field formed between $g-C_{3} N_{4}$ and CQDs, the photogenerated electrons easily transferred to the CQDs, and the photogenerated holes remained on the $\mathrm{g}-\mathrm{C}_{3} \mathrm{~N}_{4}$, thereby forming a spatial separation. Then, the $\mathrm{h}^{+}$was used for the oxidative decomposition of the dye, at the same time, the photogenerated holes were used to reduce $\mathrm{H}^{+}$to form $\mathrm{H}_{2}$, thereby achieving efficient decomposition of the dye and simultaneous hydrogen production.

\section{Materials and Method}

\subsection{Reagents and Materials}

All reagents (analytical purity) in the experiment were obtained from Sinopharm Chemical Reagent Co., Ltd. (Shanghai, China) and used without further purification. The ultrapure water used in all experiments was from a synergy ultrapure water system (Millipore).

\subsection{Synthesis of Photocatalysts}

A simple bottom-up approach was used to prepare CQDs. First, $1 \mathrm{~g}$ of citric acid was heated to $180^{\circ} \mathrm{C}$ for $20 \mathrm{~min}$. During the heating process, the color gradually changed from white to brown, and a large number of bubbles were generated. Subsequently, a $\mathrm{NaOH}$ solution $\left(0.5 \mathrm{~mol} \cdot \mathrm{L}^{-1}\right)$ was slowly added until neutral, and the mixed solution was subjected to an ultrasonic treatment for $20 \mathrm{~min}$. Then, the mixture was centrifuged at $8000 \mathrm{rpm}$ for $10 \mathrm{~min}$. After that, the supernatant was dialyzed in a dialysis bag (1 KDa molar mass) for two days to remove the salt.

The method for the preparation of $\mathrm{g}-\mathrm{C}_{3} \mathrm{~N}_{4}$ sheets $(\mathrm{CN})$ was comprised of the following steps: First, $10 \mathrm{~g}$ of urea was placed in an alumina crucible with a cover and, then, heated to $550{ }^{\circ} \mathrm{C}$ with a heating ramp of $2{ }^{\circ} \mathrm{C} \cdot \mathrm{min}^{-1}$ and maintained at this temperature for two hours. After calcination treatment, the obtained power was light yellow, implying the formation of bulk g- $\mathrm{C}_{3} \mathrm{~N}_{4}$. Then, $100 \mathrm{mg}$ bulk g- $\mathrm{C}_{3} \mathrm{~N}_{4}$ were stripped in $40 \mathrm{~mL} \mathrm{HNO}_{3}$ solution $\left(\mathrm{V}_{\mathrm{HNO}_{3}} / \mathrm{V}_{\mathrm{H}_{2} \mathrm{O}}=1: 1\right)$ at $80{ }^{\circ} \mathrm{C}$ for 1 hour. Then the obtained mixture was diluted with deionized water and adjusted to neutrality with sodium hydroxide. Subsequently, the $\mathrm{CN}$ was collected by centrifugation at $8000 \mathrm{rpm}$ for $5 \mathrm{~min}$ and washed three times with water for removal of salt.

$\mathrm{CCN}$ was prepared as follows: The mixture of $10 \mathrm{~g}$ urea with different volume of CQDs solution was heated to $550{ }^{\circ} \mathrm{C}$ at a heating rate of $2{ }^{\circ} \mathrm{C} \cdot \mathrm{min}^{-1}$ under $\mathrm{N}_{2}$ and maintained at this temperature for two hours. Then, $100 \mathrm{mg}$ obtained powder (bulk CQDs-g- $\mathrm{C}_{3} \mathrm{~N}_{4}$ ) was stripped in the $\mathrm{HNO}_{3}$ solution $\left(40 \mathrm{~mL}, \mathrm{~V}_{\mathrm{HNO}_{3}} / \mathrm{V}_{\mathrm{H}_{2} \mathrm{O}}=1: 1\right)$ at $80{ }^{\circ} \mathrm{C}$ for $1 \mathrm{~h}$. Then the obtained mixture was diluted with deionized water $(50 \mathrm{~mL})$ and adjusted to neutrality with sodium hydroxide in the ice-water bath. Subsequently, the $\mathrm{CCN}$ was collected by centrifugation at $8000 \mathrm{rpm}$ for $5 \mathrm{~min}$ and washed three times with water for removal of salt. The CQDs content was analyzed by flash 2000 Elemental analyzer, as shown in Supporting Materials. 


\subsection{Photocatalytic Reaction}

Photocatalytic dyeing wastewater purification and $\mathrm{H}_{2}$ production were investigated under BL-GHX-V photochemical reactor (BILON Corporation, China). Rhodamine B (RhB) and methylene blue (MB) were employed as the probe molecules. Before light irradiation, $10 \mathrm{mg}$ of as-prepared sample was added into $30 \mathrm{~mL}$ of dye solution $\left(15 \mathrm{mg} \cdot \mathrm{L}^{-1}\right)$ and, then, the suspension was stirred for 30 min to achieve the adsorption-desorption equilibrium in the dark. A $300 \mathrm{~W}$ Xenon lamp (320 to 780 $\mathrm{nm}$ ) was used as a light source, which was positioned $10 \mathrm{~cm}$ away from the reactor with an average light intensity of $168 \mathrm{~mW} \cdot \mathrm{cm}^{-2}$. After irradiation, the suspension was taken out and centrifuged to remove the photocatalysts before measurement. The concentration changes of RhB and MB were monitored by measuring the UV-Vis absorption of the liquid supernatants. In addition, the formed hydrogen was analyzed by gas chromatography (GC7900, Techcomp) with a thermal conductivity detector (TCD) and a $5 \AA$ molecular sieve capillary column. The carrier gas was high purity nitrogen. The detector response was calibrated by the standard mixed gas of $\mathrm{H}_{2}$ and $\mathrm{N}_{2}$, which was supplied by Henan Yuanzheng corporation.

\subsection{Characterization}

All of the phase compositions and crystal structures of the prepared samples were determined by powder X-ray diffraction (XRD) method using BRUKER D8-ADVANCE diffractometer with $\mathrm{Cu}$ $\mathrm{K} \alpha$ radiation $\left(2 \theta=10^{\circ} \sim 80^{\circ}, \lambda=0.15418 \mathrm{~nm}\right)$. The morphology of the as-prepared samples was observed by a scanning electron microscopy (SEM, Zeiss Sigma 500) and a transmission electron microscope (TEM, JEOL2010), respectively. UV-Vis diffuse reflectance spectra (DRS) of the samples were measured by Shimadzu UV-3600P UV-Vis spectrophotometer. X-ray photoelectron spectroscopy (XPS) (PHA-5400, $\mathrm{Al} \mathrm{K \alpha}$ radiation) was employed to analyze the chemical composition. The binding energy was calibrated using the $\mathrm{C} 1$ s peak $(\mathrm{BE}=284.8 \mathrm{eV})$ as standard. The photoluminescence (PL) spectra of the samples were performed on a Hitachi F-7000 spectrofluorometer equipped with a 450 W Xenon lamp. Thermogravimetric analysis of CQDs was performed by Diamond TG/DTA6300 comprehensive thermal analyzer under nitrogen. Time-resolved photoluminescence spectra (TRPL) was recorded on an FLS1000 Edinburgh analytical instrument apparatus. With a three-electrode system and $0.5 \mathrm{~mol} \cdot \mathrm{L}^{-1} \mathrm{Na}_{2} \mathrm{SO}_{4}$ aqueous solution as the electrolyte, the photocurrent response of the samples was tested by a CHI 660E electrochemical station (Chenhua, China). The $\mathrm{Ag} / \mathrm{AgCl}$ electrode and platinum wire were reference electrode and counter electrode, respectively. The glassy carbon electrodes containing the as-prepared products were served as the working electrodes.

\section{Conclusions}

In summary, we developed a facile method to prepare a novel carbon quantum dot modified g- $\mathrm{C}_{3} \mathrm{~N}_{4}(\mathrm{CCN})$, which was used to purify dye wastewaters (MB and $\mathrm{RhB}$ ) with simultaneous hydrogen production. As tested for photocatalytic activities under visible light, $\mathrm{CCN}$ displayed a significant enhancement in both $\mathrm{MB}$ and $\mathrm{RhB}$ degradation and hydrogen production efficiencies. It is worth noting that the $4 \mathrm{CCN}$ entirely degraded $\mathrm{MB}$ within 20 mins. The characterization and DFT theoretical calculation results indicated that the incorporation of CQDs into the g- $\mathrm{C}_{3} \mathrm{~N}_{4}$ matrix significantly improves the charge transfer and separation efficiency of the $\mathrm{e}^{-} / \mathrm{h}^{+}$pairs under the internal potential fields between CQDs and g- $\mathrm{C}_{3} \mathrm{~N}_{4}$. A proposed mechanism speculated that the photogenerated electrons of $g-\mathrm{C}_{3} \mathrm{~N}_{4}$ could migrate to CQDs quickly for the reduction of $\mathrm{H}^{+}$to $\mathrm{H}_{2}$, and the photogenerated holes would stayed on $\mathrm{g}-\mathrm{C}_{3} \mathrm{~N}_{4}$ for simultaneous oxidation of dyes, which would provide new lines of evidence for the wastewater purification with simultaneous energy production. 
Supplementary Materials: Supplementary materials can be found at http://www.mdpi.com/1422-0067/21/3/1052/ s1.

Author Contributions: L.Z. designed the experiments. J.Z., Y.X., and M.X. carried out the experiments. H.C., X.L., and X.Y. analyzed and discussed the results. L.Z. and J.Z. wrote the manuscript. All authors have read and agreed to the published version of the manuscript.

Funding: This research was funded by the Key Science and Technology Program of Henan Province, grant number 192102310439

Conflicts of Interest: The authors declare no conflict of interest.

\section{References}

1. Han, M.; Wang, H.; Zhao, S.; Hu, L.; Yang, L. One-step synthesis of $\mathrm{CoO} / \mathrm{g}-\mathrm{C}_{3} \mathrm{~N}_{4}$ composites by thermal decomposition for overall water splitting without sacrificial reagents. Inorg. Chem. Front. 2017, 4, 1691-1696. [CrossRef]

2. Li, R.; Li, C. Photocatalytic Water Splitting on Semiconductor-Based Photocatalysts. Adv. Catal. 2017, 60, $1-57$.

3. $\mathrm{Li}$, J.; Liu, F.; Li, Y. Fabrication of an $\mathrm{Ag} / \mathrm{Ag}_{2} \mathrm{MoO}_{4}$ plasmonic photocatalyst with enhanced photocatalytic performance for the degradation of ciprofloxacin. New J. Chem. 2018, 42, 12054-12061. [CrossRef]

4. Qian, Z.; Ming, G.; Liu, W.; Mao, Y.; Le, S.; Shang, J.; Fei, L.; Liu, X.; Kai, L.; Jiang, T. Enhancement of visible-light photocatalytic activity of silver and mesoporous carbon co-modified $\mathrm{Bi}_{2} \mathrm{WO}_{6}$. Appl. Surf. Sci. 2015, 332, 138-146.

5. Ola, O.; Maroto-Valer, M.M. Review of material design and reactor engineering on $\mathrm{TiO}_{2}$ photocatalysis for $\mathrm{CO}_{2}$ reduction. J. Photoch. Photobio. C 2015, 24, 16-42. [CrossRef]

6. Xing, J.; Fang, W.Q.; Zhao, H.J.; Yang, H.G. Inorganic photocatalysts for overall water splitting. Chem-Asian J. 2012, 7, 642-657. [CrossRef]

7. Wang, X.; Maeda, K.; Thomas, A.; Takanabe, K.; Xin, G.; Carlsson, J.M.; Domen, K.; Antonietti, M. A metal-free polymeric photocatalyst for hydrogen production from water under visible light. Nat. Mater. 2009, 8, 76-80. [CrossRef]

8. Cao, S.; Yu, J. g- $\mathrm{C}_{3} \mathrm{~N}_{4}$-Based Photocatalysts for Hydrogen Generation. J. Phys. Chem. Lett. 2014, 5, $2101-2107$. [CrossRef]

9. Li, G.; Lian, Z.; Wang, W.; Zhang, D.; Li, H. Nanotube-confinement induced size-controllable g- $\mathrm{C}_{3} \mathrm{~N}_{4}$ quantum dots modified single-crystalline $\mathrm{TiO}_{2}$ nanotube arrays for stable synergetic photoelectrocatalysis. Nano Energy 2016, 19, 446-454. [CrossRef]

10. Zhang, M.; Jiang, W.; Liu, D.; Wang, J.; Liu, Y.; Zhu, Y.; Zhu, Y. Photodegradation of phenol via $\mathrm{C}_{3} \mathrm{~N}_{4}$-agar hybrid hydrogel 3D photocatalysts with free separation. Appl. Catal. B-Environ. 2016, 183, 263-268. [CrossRef]

11. Liu, J.; Wang, H.; Chen, Z.P.; Moehwald, H.; Fiechter, S.; van de Krol, R.; Wen, L.; Jiang, L.; Antonietti, M. Microcontact-printing-assisted access of graphitic carbon nitride films with favorable textures toward photoelectrochemical application. Adv. Mater. 2015, 27, 712-718. [CrossRef] [PubMed]

12. Zhang, Z.; Jiang, D.; Li, D.; He, M.; Chen, M. Construction of $\mathrm{SnNb}_{2} \mathrm{O}_{6}$ nanosheet $/ g-\mathrm{C}_{3} \mathrm{~N}_{4}$ nanosheet two-dimensional heterostructures with improved photocatalytic activity: Synergistic effect and mechanism insight. Appl. Catal. B-Environ. 2016, 183, 113-123. [CrossRef]

13. Cui, Y.; Zhang, G.; Lin, Z.; Wang, X. Condensed and low-defected graphitic carbon nitride with enhanced photocatalytic hydrogen evolution under visible light irradiation. Appl. Catal. B-Environ. 2016, 181, 413-419. [CrossRef]

14. Wang, S.; Li, D.; Sun, C.; Yang, S.; Guan, Y.; He, H. Synthesis and characterization of g- $\mathrm{C}_{3} \mathrm{~N}_{4} / \mathrm{Ag}_{3} \mathrm{VO}_{4}$ composites with significantly enhanced visible-light photocatalytic activity for triphenylmethane dye degradation. Appl. Catal. B-Environ. 2014, 144, 885-892. [CrossRef]

15. Fang, S.; Xia, Y.; Lv, K.; Li, Q.; Sun, J.; Li, M. Effect of carbon-dots modification on the structure and photocatalytic activity of $\mathrm{g}-\mathrm{C}_{3} \mathrm{~N}_{4}$. Appl. Catal. B-Environ. 2016, 185, 225-232. [CrossRef]

16. Yan, S.C.; Li, Z.S.; Zou, Z.G. Photodegradation of rhodamine $B$ and methyl orange over boron-doped g- $C_{3} \mathrm{~N}_{4}$ under visible light irradiation. Langmuir 2010, 26, 3894-3901. [CrossRef] 
17. Zhu, B.; Xia, P.; Ho, W.; Yu, J. Isoelectric point and adsorption activity of porous g-C $\mathrm{C}_{3} \mathrm{~N}_{4}$. Appl. Surf. Sci. 2015, 344, 188-195. [CrossRef]

18. Zhang, G.; Ji, Q.; Wu, Z.; Wang, G.; Liu, H.; Qu, J.; Li, J. Facile “Spot-heating" synthesis of carbon dots/carbon nitride for solar hydrogen evolution synchronously with contaminant decomposition. Adv. Funct. Mater. 2018, 28, 1706462. [CrossRef]

19. Li, K.; Su, F.-Y.; Zhang, W.-D. Modification of $\mathrm{g}-\mathrm{C}_{3} \mathrm{~N}_{4}$ nanosheets by carbon quantum dots for highly efficient photocatalytic generation of hydrogen. Appl. Surf. Sci. 2016, 375, 110-117. [CrossRef]

20. Liu, J.; Liu, Y.; Liu, N.; Han, Y.; Zhang, X.; Huang, H.; Lifshitz, Y.; Lee, S.-T.; Zhong, J.; Kang, Z. Metal-free efficient photocatalyst for stable visible water splitting via a two-electron pathway. Science 2015, 347, 970-974. [CrossRef] [PubMed]

21. Xu, B.; Ahmed, M.B.; Zhou, J.L.; Altaee, A.; Xu, G.; Wu, M. Graphitic carbon nitride based nanocomposites for the photocatalysis of organic contaminants under visible irradiation: Progress, limitations and future directions. Sci. Total Environ. 2018, 633, 546-559. [CrossRef] [PubMed]

22. Hou, H.J.; Zhang, X.H.; Huang, D.K.; Ding, X.; Wang, S.Y.; Yang, X.L.; Li, S.Q.; Xiang, Y.G.; Chen, H. Conjugated microporous poly(benzothiadiazole)/ $/ \mathrm{TiO}_{2}$ heterojunction for visible-light-driven $\mathrm{H} 2$ production and pollutant removal. Appl. Catal. B-Environ. 2017, 203, 563-571. [CrossRef]

23. Zhang, S.; Wang, L.; Liu, C.; Luo, J.; Crittenden, J.; Liu, X.; Cai, T.; Yuan, J.; Pei, Y.; Liu, Y. Photocatalytic wastewater purification with simultaneous hydrogen production using $\mathrm{MoS}_{2}$ QD-decorated hierarchical assembly of $\mathrm{ZnIn}_{2} \mathrm{~S}_{4}$ on reduced graphene oxide photocatalyst. Water res. 2017, 121, 11-19. [CrossRef] [PubMed]

24. Jiang, X.H.; Wang, L.C.; Yu, F.; Nie, Y.C.; Xing, Q.J.; Liu, X.; Pei, Y.; Zou, J.P.; Dai, W.L. Photodegradation of organic pollutants coupled with simultaneous photocatalytic evolution of hydrogen using quantum-dot-modified $\mathrm{g}-\mathrm{C}_{3} \mathrm{~N}_{4}$ catalysts under visible-light irradiation. ACS Sustain. Chem. Eng. 2018, 6, 12695-12705. [CrossRef]

25. Bai, X.; Wang, L.; Zong, R.; Zhu, Y. Photocatalytic activity enhanced via g- $\mathrm{C}_{3} \mathrm{~N}_{4}$ nanoplates to nanorods. J. Phys. Chem. C 2013, 117, 9952-9961. [CrossRef]

26. Wang, J.; Yang, Z.; Yao, W.Q.; Gao, X.X.; Tao, D.P. Defects modified in the exfoliation of g- $\mathrm{C}_{3} \mathrm{~N}_{4}$ nanosheets via a self-assembly process for improved hydrogen evolution performance. Appl. Catal. B-Environ. 2018, 238, 629-637. [CrossRef]

27. Xue, B.; Jiang, H.Y.; Mao, F.; Ma, C.C.; Wu, J.K. Microwave-assisted one-step rapid synthesis of ternary $\mathrm{Ag} / \mathrm{Ag}_{2} \mathrm{~S} / \mathrm{g}-\mathrm{C}_{3} \mathrm{~N}_{4}$ heterojunction photocatalysts for improved visible-light induced photodegradation of organic pollutant. J. Photoch. Photobio. A 2017, 353, 557-563. [CrossRef]

28. Li, Y.; Feng, X.; Lu, Z.; Yin, H.; Liu, F.; Xiang, Q. Enhanced photocatalytic $\mathrm{H}_{2}$-production activity of C-dots modified g- $\mathrm{C}_{3} \mathrm{~N}_{4} / \mathrm{TiO}_{2}$ nanosheets composites. J. Colloid Interf. Sci. 2018, 513, 866-876. [CrossRef]

29. Sun, C.; Xu, Q.; Xie, Y.; Ling, Y.; Jiao, J.; Zhu, H.; Zhao, J.; Liu, X.; Hu, B.; Zhou, D. High-efficient one-pot synthesis of carbon quantum dots decorating $\mathrm{Bi}_{2} \mathrm{MoO}_{6}$ nanosheets heterostructure with enhanced visible-light photocatalytic properties. J. Alloy. Comp. 2017, 723, 333-344. [CrossRef]

30. Chen, J.; Che, H.; Huang, K.; Liu, C.; Shi, W. Fabrication of a ternary plasmonic photocatalyst CQDs/Ag/Ag $2 \mathrm{O}$ to harness charge flow for photocatalytic elimination of pollutants. Appl. Catal. B-Environ. 2016, 192, $134-144$. [CrossRef]

31. Schwinghammer, K.; Mesch, M.B.; Duppel, V.; Ziegler, C.; Senker, J.; Lotsch, B.V. Crystalline Carbon Nitride Nanosheets for Improved Visible-Light Hydrogen Evolution. J. Am. Chem. Soc. 2014, 136, 1730-1733. [CrossRef] [PubMed]

(C) 2020 by the authors. Licensee MDPI, Basel, Switzerland. This article is an open access article distributed under the terms and conditions of the Creative Commons Attribution (CC BY) license (http://creativecommons.org/licenses/by/4.0/). 